\title{
Prevalence of Molar Incisor Hypomineralization and its Relation with Dental Caries in School Children of Udupi District, South India
}

\author{
${ }^{1}$ Abhinav N Tadikonda, ${ }^{2}$ Shashidhar Acharya, ${ }^{3}$ Kalyana Chakravarthy Pentapati
}

\begin{abstract}
Aim: To evaluate the prevalence of molar incisor hypomineralization $(\mathrm{MIH})$ and its relationship with dental caries in school children of Udupi district.
\end{abstract}

Materials and methods: A total of 352 school children were recruited for this study. The European Academy of Pediatric Dentistry (EAPD) 2003, criteria were followed for diagnosis of $\mathrm{MIH}$. Dental caries was recorded using World Health Organization (WHO) guidelines (1997) under natural day light.

Results: The prevalence of MIH was seen to be $27 \%(n=95)$ A total of 323 teeth had hypomineralization (106 were incisors and 217 were molars). The lower molars $(n=127)$ were more frequently affected than the upper molars $(n=90)$. Overall the maxillary incisors $(n=68)$ were more affected than the mandibular incisors $(n=38)$. Amongst the children with $\mathrm{MIH}$, the mean number of decayed teeth was significantly lower than mean number of hypomineralized teeth in first permanent molars and first permanent molars and incisors $(p<0.001$ and $<0.001)$ respectively. The mean decayed teeth in first permanent molar and incisors were significantly higher in subjects with $\mathrm{MIH}$ than without $\mathrm{MIH}(\mathrm{p}<0.001)$. Poisson regression analysis showed a significant positive association between $\mathrm{MIH}$ and dental caries $(B=1.43 ; p<0.001)$.

Conclusion: The prevalence of $\mathrm{MIH}$ was relatively high and was associated with dental caries.

Keywords: Caries, Hypomineralization, Incisors, Molar, Prevalence.

How to cite this article: Tadikonda AN, Acharya S, Pentapati KC. Prevalence of Molar Incisor Hypomineralization and its Relation with Dental Caries in School Children of Udupi District, South India. World J Dent 2015;6(3):143-146.

Source of support: Nil

Conflict of interest: None

\section{INTRODUCTION}

Molar incisor hypomineralization (MIH) is defined as 'demarcated, qualitative defects of enamel of systemic

\footnotetext{
${ }^{1}$ Postgraduate, ${ }^{2}$ Professor and Head, ${ }^{3}$ Associate Professor

${ }^{1-3}$ Department of Public Health Dentistry, Manipal College of Dental Sciences, Manipal University, Manipal, Karnataka, India

Corresponding Author: Kalyana Chakravarthy Pentapati Associate Professor, Department of Public Health Dentistry, Manipal College of Dental Sciences, Manipal University, Manipal, Karnataka India, Phone: +91-991-603-6303, e-mail: drkalyan81@gmail.com
}

origin, affecting one or more permanent molars [usually the first permanent molars (FPMs)] with or without involvement of the incisor teeth. ${ }^{1}$ Preliminary studies were conducted by Koch et $\mathrm{al}^{2}$ following which many authors reported with various clinical indices and criteria. ${ }^{3-7}$

The prevalence of MIH was not well documented due to several diagnostic classifications in the literature. The global prevalence of MIH ranged from 2.4 to $40.2 \%$. Majority of the studies that reported MIH were from European countries with a prevalence range of 3.6 to $37.5 \% .{ }^{2,8}$ Prevalence in middle and South East Asian countries ranged from 9.25 to $20.2 \%{ }^{9-12}$ Prevalence data from low income countries like India were scant and reported a prevalence of 6.31 to $9.46 \% .{ }^{13-16}$

The defect is clinically presented as demarcated enamel opacities of different colors, occasionally undergoing posteruptive breakdown (PEB) due to soft and porous enamel. This may result in atypical cavities or even complete coronal distortion, requiring extensive restorative treatment. ${ }^{17,18}$ Patients and parents were reported to complain of MIH with symptoms including esthetic problems, rapid dental wear and loss of enamel, inclination to caries, dental hypersensitivity and eventually tooth loss. ${ }^{6}$ Children suffering from MIH often demonstrate behavior management problems and dental fear because of the difficulties in achieving adequate anesthesia. Moreover, the altered and porous enamel structure makes bonding risky, leading to defective fillings and frequent retreatments. ${ }^{19,20}$ Despite the higher treatment demands, restorative treatments for these teeth are challenging for both the patient and the dentist. ${ }^{19}$

Due to severe clinical manifestations and their consequences associated with $\mathrm{MIH}$, knowledge about its prevalence and risk factors in developing countries is needed. The aim of the present study was to evaluate the prevalence of $\mathrm{MIH}$ and its relationship with dental caries in school children of Udupi district.

\section{MATERIALS AND METHODS}

We conducted a cross-sectional survey between 11 and 15 years school children of Udupi district. Permission to conduct the study was obtained from school authorities, informed consent from parents and verbal consent from 
children was also sought. The study was approved by the Institutional Ethics Committee of Manipal University, Manipal.

Subjects who were present on the day of examination were invited to participate in this study. Subjects with generalized developmental enamel defects, such as amelogenesis imperfecta and dental fluorosis were excluded from the study.

Sample size was calculated based on the prevalence reported from previous studies (6\%) with 95\% confidence level, $5 \%$ margin of error, with a design effect of 1.5 and expected response rate of $80 \%$ for two clusters. It was seen that the minimum sample size needed was 325. All the children who were in the age group of 11 to 15 years, from four different randomly selected schools (two private and two government) in Udupi district were invited to participate in the study ( $n=372)$.

A single trained and calibrated examiner (ATN) performed all the examinations with the help of a recording clerk. A photo calibration session was conducted using 30 clinical images (15 cases of $\mathrm{MIH}$ and 15 cases with other enamel defects). The validity of using clinical photographs to study enamel defects has been established previously. ${ }^{21}$ Intraexaminer reliability was assessed using Cohen's Kappa. A value of 0.91 suggested that there was almost perfect agreement.

Clinical examinations for all children were conducted in natural lighting conditions at the school premises under wet mouth conditions to distinguish from other enamel lesions. Detection of MIH was done using the European Academy of Pediatric Dentistry, (EAPD) criteria. ${ }^{22}$ Dental caries was recorded using World Health Organization (WHO) oral health survey guidelines (1997), plain mouth mirrors and community periodontal index (CPI) probes. A total of 12 index teeth (four first permanent molars and eight incisors) were examined for hypomineralization and dental caries.

\section{STATISTICAL ANALYSIS}

All the analyses were done using statistical package for social sciences (SPSS) version 18. A p-value of $<0.05$ was considered statistically significant. Mann-Whitney $\mathrm{U}$ test was used to compare caries experience between subjects with and without $\mathrm{MIH}$. Wilcoxon sign ranked test was used to compare mean number of decayed and hypomineralized teeth among the subjects with $\mathrm{MIH}$. We used generalized linear models (GLMs) with a poisson log-linear link function to determine the association between enamel hypomineralization and dental caries.

\section{RESULTS}

A total of 352 children aged between 11 and 15 years completed all the stages of survey. Children excluded were due to dental fluorosis, non-residents of study area and ongoing orthodontic treatment $(n=24)$. The mean age of the children was $12.97 \pm 1.2$ years with $51.1 \%$ being males.

The prevalence of $\mathrm{MIH}$ was $27 \%(\mathrm{n}=95)$. Out of the 95 subjects affected with MIH, a total of 323 affected teeth had hypomineralization (106 were incisors and 217 were molars). The lower molars $(n=127)$ were more frequently affected than the upper molars $(n=90)$ of which the lower left molar $(n=68)$ was the highest involved followed by the right mandibular molar $(n=59)$. Overall, the maxillary incisors $(n=68)$ were more affected than the mandibular incisors $(n=38)$. Among the incisors, the more commonly affected tooth was the right maxillary central incisor $(n=28)$.

The mean number of decayed teeth was significantly lower than the mean number of hypomineralized teeth in FPMs $(p<0.001)$. Similarly, the mean number of decayed teeth was significantly lower than the mean number of hypomineralized teeth in first permanent molars and incisors $(p<0.001)$ (Table 1$)$. The mean decayed teeth in first permanent molar and incisors was significantly higher in subjects with MIH than without $\mathrm{MIH}(\mathrm{p}<0.001)$ (Table 2). Poisson regression analysis was done with predictor as $\mathrm{MIH}$ and outcome as dental caries. It was seen that there was significant positive association between $\mathrm{MIH}$ and dental caries $(\mathrm{B}=1.43 ; \mathrm{p}<0.001)$ (Table 3).

Table 1: Comparison of mean number of decayed teeth and hypomineralized teeth in $\mathrm{MIH}$ subjects

\begin{tabular}{|c|c|c|c|c|c|}
\hline \multirow[b]{2}{*}{ Index teeth } & \multicolumn{2}{|c|}{ Decayed teeth } & \multicolumn{2}{|c|}{$\begin{array}{l}\text { Hypomineralized } \\
\text { teeth }\end{array}$} & \multirow[b]{2}{*}{$p$-value } \\
\hline & Mean & $S D$ & Mean & $S D$ & \\
\hline $\begin{array}{l}\text { First permanent } \\
\text { molars }\end{array}$ & 1.06 & 1.17 & 2.28 & 1.11 & $<0.001$ \\
\hline $\begin{array}{l}\text { First permanent } \\
\text { molars and } \\
\text { incisors }\end{array}$ & 1.06 & 1.17 & 3.40 & 2.00 & $<0.001$ \\
\hline
\end{tabular}

Table 2: Comparison of mean number of decayed teeth in $\mathrm{MIH}$ and control subjects

\begin{tabular}{lllll}
\hline & $N$ & Mean & $S D$ & $p$-value \\
\hline No MIH & 257 & 0.01 & 0.06 & $<0.001 ; \mathrm{S}$ \\
MIH & 95 & 1.06 & 1.17 & \\
\hline
\end{tabular}

\section{S: Significant}

Table 3: Poisson regression analysis to evaluate the relationship between caries (outcome) and MIH (predictor)

\begin{tabular}{|c|c|c|c|c|c|c|}
\hline \multirow[b]{2}{*}{ Parameter } & \multicolumn{4}{|c|}{ Hypothesis test } & \multicolumn{2}{|c|}{$\begin{array}{l}95 \% \text { Confidence } \\
\text { interval }\end{array}$} \\
\hline & $\begin{array}{l}\text { Wald Chi- } \\
\text { square }\end{array}$ & $d f$ & $p$-value & $\begin{array}{l}\text { Exp } \\
\text { (B) }\end{array}$ & Lower & Upper \\
\hline $\mathrm{MIH}$ & 194.29 & 1 & $<0.001$ & 1.43 & 1.36 & 1.5 \\
\hline
\end{tabular}




\section{DISCUSSION}

Our study evaluated the prevalence of MIH and its relationship with dental caries in school children of Udupi district, Karnataka. The prevalence of MIH in our study (27\%) was relatively higher than the other Indian studies (6.31-9.46\%). ${ }^{13,15,16}$ However, such high prevalence was reported elsewhere by many authors. ${ }^{3,8,23-25}$ These differences might be due to the different age cohorts, missing/ unerupted, extracted teeth, criteria used to define $\mathrm{MIH}$ or due to an actual difference in the prevalence rates. Many putative and possible risk factors have been noted in the past including antibiotic use, fevers (especially in the first year), chicken pox, ear infections, tonsillitis, asthma and allergies. ${ }^{5,26-29}$ Perinatal conditions including infections and illnesses during pregnancy, birth prematurity, birth complications, and family histories of 'enamel defects' have also been implicated. 5,26,28,29 The higher prevalence of $\mathrm{MIH}$ in this region may be due to the clustering effect of risk factors which could not be evaluated by the crosssectional study design.

Although, 8 years and above is considered the best time to observe MIH (all index teeth would have erupted), we had considered 11 to 15 years of age keeping in view that enough time would have elapsed for the caries to manifest.

Among the children with $\mathrm{MIH}$, the mean number of decayed teeth was significantly lower than mean number of hypomineralized teeth in the first permanent molars. Similarly, the mean number of decayed teeth was significantly lower than the mean number of hypomineralized teeth in first permanent molars and incisors. Although the difference in the mean decayed teeth and hypomineralized teeth was significant, it could be inferred that there were significant number of decayed teeth amongst the hypomineralized teeth. The mean number of decayed teeth was accounted only by the first permanent molars while the incisors did not contribute to the total decayed teeth. This suggested that in the presence of MIH, tooth morphology and fissure patterns would be more conducive for the development of caries.

The mean number of decayed teeth in the first permanent molars and incisors were significantly higher in subjects with MIH than without MIH which was consistent with the previous studies. ${ }^{6,9}$ This was further quantified with poisson regression analysis which showed that among the subjects with $\mathrm{MIH}$, there was 1.43 times higher score of decayed teeth than those who did not have MIH which was in line with the previous studies. ${ }^{11}$ This could be due to posteruptive breakdown (PEB) which might increase plaque accumulations, eventually leading to caries initiation and progression. However, no such association between caries and MIH was reported by Heitmuller et al (2013) which might possibly be due to the very low caries risk in the study population. ${ }^{30}$

Also, in our study we noted substantial number of individuals who did not have hypomineralization in molars but exclusively in incisors. Such, individuals may not be categorized as $\mathrm{MIH}$ as per the working definition but still pose considerable disease burden and challenges to dental health care provider. Future classifications could include the same, so that accurate prevalence rates can be reported. Further, longitudinal studies are needed to plausibly confirm the role of hypomineralization in caries initiation and progression.

\section{REFERENCES}

1. Weerheijm KL, Jälevik B, Alaluusua S. Molarincisor hypomineralisation. Caries Res 2001;35(5):390-391.

2. Koch G, Hallonsten A-L, Ludvigsson N, et al. Epidemiological study of idiopathic enamel hypomineralisation in permanent teeth of Swedish children. Community Dent Oral Epidemiol 1987;15(5):279-285.

3. Alaluusua S, Lukinmaa P-L, Koskimies M, et al. Developmental enamel defects associated with long breast feeding. Eur J Oral Sci 1996a;104(5-6):493-497.

4. Alaluusua S, Lukinmaa P-L, Vartiainen T, et al. Polychlorinated dibenzo-p dioxins and dibenzofurans via mother's milk may cause developmental defects in the child's teeth. Environ Toxicol Pharmacol 1996b;1(3):193-197.

5. Jälevik B, Klingberg G, Barregard L, Norén JG. The prevalence of demarcated opacities in permanent first molars in a group of Swedish children. Acta Odontol Scand 2001;59(5):255-260.

6. Leppäniemi A, Lukinmaa PL, Alaluusua S. Nonfluoride hypomineralisations in the permanent first molars and their impact on the treatment need. Caries Res 2001;35(1):36-40.

7. Weerheijm KL, Groen HJ, Beentjes VE, Poorterman JH. Prevalence of cheese molars in 11-year-old Dutch children. J Dent Child 2001 Jul-Aug;68(4):259-262.

8. Wogelius P, Haubek D, Poulsen S. Prevalence and distribution of demarcated opacities in permanent 1st molars and incisors in 6 to 8-years-old Danish children. Acta Odontol Scand 2008;66(1):58-64.

9. Cho SY, Ki Y, Chu V. Molar incisor hypomineralization in Hong Kong Chinese children. Int J Paediatr Dent 2008;18(5): 348-352.

10. Ghanim A, Morgan M, Mariño R, Bailey D, Manton D. Molar incisor hypomineralisation: prevalence and defect characteristics in Iraqi children. Int J Paediatr Dent 2011;21(6): 413-421.

11. Pitiphat W, Ratchanekorn S, Nusara C, Ajiravudh S. Molar incisor hypomineralization and dental caries in 6- to 7-yearold Thai children. Pediatr Dent 2014;36(7):478-482.

12. Zawaideh FI, Al-Jundi SH, Al-Jaljoli MH. Molar incisor hypomineralisation: prevalence in Jordanian children and clinical characteristics. Eur Arch Paediatr Dent 2011;12(1):31-36.

13. Bhaskar SA, Hegde S. Molar Incisor hypomineralisation: prevalence, severity and clinical characteristics in 8 to 13 years old children of Udaipur, India. J Ind Soc Pedod Prev Dent 2014;32(4):322-329.

14. Mittal N, Sharma BB. Molar incisor hypomineralization: prevalence and defect characteristics in Indian school children. J Cranio Max Dis 2015;4(1):49-56. 
15. Mittal NP, Goyal A, Gauba K, Kapur A. Molar incisor hypomineralisation: prevalence and clinical presentation in school children of the northern region of India. Eur Arch Paediatr Dent 2014;15(1):11-18.

16. Parikh DR, Ganesh M, Bhaskar V. Prevalence and characteristics of molar incisor hypomineralisation (MIH) in the child population residing in Gandhinagar, Gujarat, India. Eur Arch Paediatr Dent 2012;13(1):21-26.

17. Lygidakis NA, Chaliasou A, Siounas G. Evaluation of composite restorations in hypomineralised permanent molars: a 4 years clinical study. Eur J Paediatr Dent 2003;3(3):143-148.

18. Mathu-Muju K, Wright JT. Diagnosis and treatment of molar incisor hypomineralization. Compend Contin Educ Dent 2006;27(11):604-610.

19. Jälevik B, Klingberg GA. Dental treatment, dental fear and behaviour management problems in children with severe enamel hypomineralisation of their first permanent molars. Int J Paediatr Dent 2002;12(1):24-32.

20. Kotsanos N, Kaklamanos EG, Arapostathis K. Treatment management of first permanent molars in children with molarincisor hypomineralisation. Eur J Paediatr Dent 2005;6(4):179-184.

21. Sabieha AM, Rock WP. A comparison of clinical and photographic scoring using the TF and modified DDE index. Community Dent Health 1998;15(2):82-87.

22. Lygidakis NA, Wong F, Jälevik B, Vierrou AM, Alaluusua S, Espelid I. Best clinical practice guidance for clinicians dealing with children presenting with molarincisor-hypomineralization (MIH): an EAPD policy document. Eur Arch Paediatr Dent 2010;11(2):75-81.
23. Arrow P. Risk factors in the occurrence of enamel defects of the first permanent molars among school children in Western Australia. Community Dent Oral Epidemiol 2009; 37(5):405-415.

24. Balmer RC, Laskey D, Mahoney E. Toumba KJ. Prevalence of enamel defects and $\mathrm{MIH}$ in non-fluoridated and fluoridated communities. Eur J Paediatr Dent 2005;6(4):209-212.

25. Soviero V, Haubeck D, Trindae C, Matta TD, Poulsen S. Prevalence and distribution of demarcated opacities and their sequelae in permanent 1st molars and incisors in 7 to 13 years old Brazilian children. Acta Odontol Scand 2009;67(3): 170-175.

26. Beentjes VE, Weerheijm KL, Groen HJ. Factors involved in the aetiology of molar-incisor hypomineralisation (MIH). Eur J Paediatr Dent 2002;3(1):9-13.

27. Chawla N, Messer LB, Silva M. Clinical studies on molar incisor hypomineralisation. Part 1: distribution and putative associations. Eur Arch Paediatr Dent 2008;9(4):180-190.

28. Lygidakis NA, Dimou G, Marinou D. Molar incisor hypomineralisation $(\mathrm{MIH})$. A retrospective clinical study in Greek children II. Possible medical aetiological factors. Eur Arch Paediatr Dent 2008b;9(4):207-217.

29. Van Amerongen W, Kreulen C. Cheese molars: a pilot study of the etiology of hypocalcifications in first permanent molars. J Dent Child 1995;62(4):266-269.

30. Heitmuller D, Thiering E, Hoffmann U, et al. Is there a positive relationship between molar incisor hypomineralisations and the presence of dental caries? Int J Paediatr Dent 2013;23(2): 116-124. 